\title{
Nepotism or Family Tradition?: \\ A Study of NASCAR Drivers
}

by

Peter A. Groothuis

Associate Professor

Department of Economics

Appalachian State University

Boone, NC 28608

and

Jana D. Groothuis

Boone, NC 28607

Summer 2006 
ABSTRACT: Of the drivers who raced NASCAR cup series in 2005, 23 of 76 had family connections of either being a son, brother or father of current or former drivers. Given the family connections, some have suggested that the N in NASCAR stands for nepotism. The family tradition of career following, however, is not unique to NASCAR. We see this pattern in many careers such as business, law, politics, agriculture, medicine and entertainment. There are many reasons why children enter the same career as their parents. These include physical-capital transfer, human-capital transfer, brand-nameloyalty transfer, and nepotism. Using a panel data of career statistics for drivers from the last 30 years, we test to see which model best explains career following in NASCAR racing. Our results suggest that the $\mathrm{N}$ in NASCAR does not stand for nepotism. Sons, do not have longer careers than non family connected drivers, given the same level of performance. We do find, however, that fathers end their careers earlier than performance indicates when a son enters into cup competition. This could be due to a son's ability to extend a brand name across generations. The extension of a brand name also occurs with second brothers who benefit from the first brother's name and having longer careers than performance indicates. If nepotism exits, it occurs only with the second brothers. 
Throughout the history of NASCAR there has been a family tradition of drivers. Of the drivers who raced NASCAR cup series in 2005, 23 of 76 had family connections of either being a son, brother or father of current or former drivers. Given the family connections, some have suggested that the $\mathrm{N}$ in NASCAR stands for nepotism. The family tradition of career following, however, is not unique to NASCAR. We see this pattern in many careers such as business, law, politics, agriculture, medicine and entertainment. There are many reasons why children enter the same career as their parents. These include physical-capital transfer, human-capital transfer, brand-nameloyalty transfer, and nepotism.

Using a panel data of career statistics for drivers from the last 30 years, we test to see which model best explains career following in NASCAR racing. Unlike previous studies that look at only parent child career following, we also focus on second brothers following in the career of their first brother in racing. To test the implications of each model, we focus on career length to see if it is family connection or performance on the track that determines career length.

\section{Section 1: Theory}

In a series of articles, Laband and Lentz (1983a, 1983b, 1984, 1985, 1989, 1990a 1990b and 1992) have tested different industries to study why children follow in their parent's career paths. Their results differ by industry. For instance, farmer's children who also become farmers tend to stay on the same land their parents farmed (Laband and Lentz 1984) suggesting both human and physical capital transfer. Nearly fifty percent of 
self-employed proprietors are second generation business owners, suggesting possible brand loyalty, human-capital transfer, and or physical-capital transfer. Baseball players who are sons of former players tend to play the same position as their fathers, (Laband and Lentz 1990) also suggesting human capital transfer.

Politicians' children are more likely to become politicians and tend to do better than their parents in terms of elections (Laband and Lentz 1985) supporting both brand name loyalty and human-capital transfer. Children of lawyers who follow their parents into law tend to do better the first years of law practice than non-lawyer children. This is due to human capital transfer and potentially nepotism (Laband and Lentz 1992). Doctors' children are found to have an advantage in medical school admissions even if they have lower test scores or grades. This suggests nepotism in the admissions process (Laband and Lentz 1990b). We know of no articles that focus on sibling career following. In the NASCAR cup series, human-capital transfer, physical-capital transfer, nepotism and brand name could all play a role in why a child follows their parent into a racing career.

\section{Human-Capital Transfer}

Formal education is the traditional way to acquire general human capital. Firm specific human capital is acquired on the job and is usually a shared investment. (Becker 1993) Many occupations skills are learned on the job, such as farming and sole proprietor ownership. Skills for a sports career are industry specific falling in between pure general training and firm specific training. Sports skills are usually obtained by participating in the sport on amateur level through learning by doing. In baseball and hockey, minor league teams develop the talent of players. Basketball and football players 
usually develop their skill for the professional leagues through college athletics. In racing, there are short tracks, Craftsman Truck and Busch series where drivers develop their skills. Children of racers and younger brothers of racers may grow up in the tradition of racing and acquire skills by being on the track with their families.

\section{Physical-Capital Transfer and Nepotism}

A driver's performance in a race depends not only on their skills but also the quality of the car they drive, and of their pit crew. Car quality depends upon engineering, testing and fabrication. In addition, each driver has many cars to race, depending upon the track. Ultimately, the cost of racing for each driver is a multi-million dollar enterprise. Many former drivers become car owners. Some turn to their sons to be

drivers. It is in this hiring that nepotism may be present. Nepotism, in many ways, is the opposite of Becker’s employer prejudiced based discrimination. (Becker 1962) In Becker's model, firm owners get a disutility in hiring members of a particular group. Nepotism suggests that firm owners get a positive utility of hiring members of their own family. If this is the case, sons of drivers will be less productive on the track than nonfamily connected drivers. Car owners are willing to accept lower quality racers because of the utility they derive from employing family members.

\section{Brand Name Loyalty}

NASCAR racing depends upon corporate sponsorship to fund cars and racing teams. Corporations fund cars to provide advertisements for their products and exposure of their corporate names. Drivers in many ways become the spokesperson of the corporation that sponsors the team. Thus, the driver's last name becomes associated with a corporation and even a brand on its own. Laband and Lentz (1985) suggest that 
occupational following may be an efficient mechanism for the transfer of rents across generations when the family name embodies goodwill. They argue that this occurs in politics with family members running on the family name such as the Kennedy, Dole, Clinton and Bush.

Overall, there are many reasons for career following that are not all mutually exclusive. Human-capital transfer suggests that family members have access to learning that makes drivers more productive, and at a younger age. Nepotism suggests that drivers have longer careers than their productivity indicates. Brand name loyalty suggests that fathers or first brothers can develop brand loyalty on which sons and second brothers can capitalize.

\section{Section 2: The Data}

Our data is a panel of all individuals who participated in the top NASCAR cup series from 1975 through 2005. This thirty-year panel consists of 691 drivers and 2848 observations. To capture the overall length of a driver's career, our data contains both stock and flow samples. A stock sample is composed of all ongoing careers at the start of the panel in 1975. These left-censored data are easily included because we know how many years each driver had driven in the NASCAR cup series prior to 1975. Our stock sample has 97 drivers who had an average tenure of 7 years as they entered the 1975 season. Including a stock sample, captures information on drivers whose careers may be longer than the panel data set. For instance, one driver during this period had a career length of 35 years. Using only stock data would under represent short-career drivers, so we also include flow data. 
A flow sample includes all careers that start between 1975 and 2005. This sample captures many short careers in NASCAR. For instance, during this period, 125 drivers had one-year careers. Including only flow data would allow for no careers longer than the 30 years. As with most panels, our data is also right-censored where many careers were ongoing when our sample ended in 2005. Our right-censored data includes only flow observations. To estimate a duration model of stock and flow data, we use a technique developed by Berger and Black (1999). This technique was also used by Groothuis and Hill (2004) to test for exit discrimination in the NBA.

In table one; we report the overall means of the variables in our panel. The variables in our data include both season-variant and season-invariant data. Our seasoninvariant data include the drivers's family relationship including dummy variables on whether he is a father, son, first brother or second brother in a racing family. The father dummy variable indicates whether a driver has a son who became a NASCAR driver. Its mean is 0.065 indicating that on average $6.5 \%$ of racers have sons who follow them into racing. The son dummy variable indicates if the driver's father was a NASCAR driver. Its mean is 0.107 indicating that on average 10.7 percent of racers are sons of racers. First brother is a dummy variable that indicates if the driver had a brother that followed him into racing. Its mean is 0.07 . The second brother dummy variable is equal to one if the driver had a brother that had preceded him into NASCAR racing. Its mean is 0.05. Some drivers met more than one category, for instance Bobby Allison is both a first brother and a father to other NASCAR drivers.

Our season-variant data includes age as well as performance data such as wins, top fives, top tens, and rank. The average number of starts per driver is about 13, per 
season wins 0.34 , top five finishes per season 1.7, and top ten finishes per season 3.36. The average driver rank in the standings is 51.1. We also report the average age of a driver is about 37.

In table 2, we report the means by family status, comparing those with family connections to those with no family connections. We find that all family connections do better than a driver with no family connections in terms of performance variables. We also find that on average fathers tend to do better than sons, while second brothers do worse than first brothers. The average career length, as measured by all non-right censored data ranges from five years for no family connected drivers to fifteen and a half years for drivers who are fathers. We also find that son's careers tend to be shorter than father's careers and second brothers have shorter careers than do first brothers. Looking at the average age of the beginning of career, we find that sons and second brothers start their careers earlier than do fathers or first brothers. Fathers and first brothers are the oldest on average when ending their careers.

On the surface, the means seem to indicate nepotism, where sons and first brothers ride on the reputations of family in the NASCAR cup series racing. To further explore the importance of family relations and determine if nepotism exists in NASCAR, we analyze the data using both non-parametric and semi-parametric techniques.

\section{Section 3: Non-parametric Estimates of Career Duration}

To help understand career duration in the NASCAR racing, we calculate yearly hazard functions as:

$$
h_{t}=d_{t} / n_{t},
$$


where $d_{t}$ is the number of drivers who end their career in year $t$ and $n_{t}$ is the number of drivers at risk of ending their career in year $t$. The hazard rate can be interpreted as the percentage of drivers who exited NASCAR, given they have acquired some level of tenure. In table 3, we report the total hazard rate and the hazard rate for both drivers with no family connections and with family connections.

In Figure 1, we plot the hazard functions by race where series 1 is the hazard rate for drivers without family connections and series 2 the hazard rate for family connected drivers. The non-family connected plot shows that the hazard rate gradually declines for the first eight years of tenure and then levels out at 15 percent until a racer has 20 years of experience. Family connected drivers follows a relatively flat pattern with some jumps around ten percent. We suggest that the pattern for non-family connected drivers, with the initial downturn, occurs as individuals are sorted from NASCAR cup series racing. Comparing the two plots, show family connected drivers are less likely to exit NASCAR racing with their hazard plot lower than the non-family connected hazard rate for the first 15 years of the plot. After 15 years, the family connected plot and non-family plot cross many times. In the next section we analyze career duration using semi-paremetric techniques to control for differences in productivity.

\section{Section 4: Semi-parametric Estimates of Career Duration}

We estimate semi-parametric hazard functions following Berger and Black (1999), Groothuis and Hill (2004), and Berger, Black and Scott (2005). Because our data is at the season level, we calculate our hazard model as a discrete random variable. As with Groothuis and Hill (2004), we model the durations of a single spell. We also 
assume a homogeneous environment so that the length of the spell is uncorrelated with the calendar time in which the spell begins, except for a time trend variable. This assumption lets us treat all the drivers' tenure as the same, regardless of when it occurred in the panel study. For instance, all fourth year drivers are considered to have the same base line hazard, regardless of calendar time. This indicates that a fourth year driver in 1978 has the same baseline hazard as a fourth year driver 1997, with the exception of a time trend.

To understand how stock data influences a likelihood function, we follow the notation of Berger, and Black (2001). Suppose the probability mass function (pmf) of durations is defined as:

$$
f(t, x, \beta) \text {, }
$$

where $t$ is the duration of the career, $\mathrm{x}$ is a vector of performance and personal characteristics, and $\beta$ is a vector of parameters. Now denote $F(t, x, \beta)$ as the cumulative distribution function; then the probability that a career lasts at least $t^{\circ}$ years is simply 1 $\mathrm{F}\left(\mathrm{t}^{\circ}, \mathrm{x}, \beta\right)$. If we define the hazard function as $\mathrm{h}(\mathrm{t}, \mathrm{x}, \beta) \equiv \mathrm{f}(\mathrm{t}, \mathrm{x}, \beta) / \mathrm{S}(\mathrm{t}, \mathrm{x}, \beta)$ and apply the definition of conditional probabilities, we may express the pmf as

$$
f\left(t_{i}, x_{i}, \beta\right)=\prod_{j=0}^{t_{i}-1}\left[1-h\left(j, x_{i}, \beta\right)\right] h\left(t_{i}, x_{i}, \beta\right) .
$$

If we have a sample of $n$ observations, $\left\{t_{1}, t_{2}, \ldots, t_{n}\right\}$, the likelihood function of the sample is

$$
L(\beta)=\prod_{i=1}^{n} f\left(t_{i}, x_{i}, \beta\right)=\prod_{i=1}^{n}\left(\prod_{j=1}^{t_{i}-1}\left[1-h\left(j, x_{i}, \beta\right)\right] h\left(t_{i}, x_{i}, \beta\right)\right) .
$$


Often it is not possible to observe all careers until they end, hence careers are often rightcensored. Let the set A be the set of all observations where the driver's careers are completed and the set B be the set of all observations where the careers are right censored. In this case, A and B are disjoint sets whose union is exactly the set of observations. For the set of right-censored observations, all we know is that the actual length of the career is greater than $t_{\mathrm{i}}$, the observed length of the career up through the last year. We know that the actual length of the career is longer than we observe and the contribution of these observations to the likelihood function is just the survivor function, $\mathrm{S}\left(\mathrm{t}_{\mathrm{i}}, \mathrm{X}_{\mathrm{i}}, \beta\right)$. Thus, we may write the likelihood function as

$$
\begin{aligned}
L(\beta) & =\prod_{i \in A}\left(\prod_{j=1}^{t_{i}-1}\left[1-h\left(j, x_{i}, \beta\right)\right] h\left(t_{i}, x_{i}, \beta\right)\right) \times \prod_{i \in B} s\left(t_{i}, x_{i}, \beta\right) \\
& =\prod_{i \in A}\left(\prod_{j=1}^{t_{i}-1}\left[1-h\left(j, x_{i}, \beta\right)\right] h\left(t_{i}, x_{i}, \beta\right)\right) \times \prod_{i \in B}\left(\prod_{j=1}^{t_{i}-1}\left[1-h\left(j, x_{i}, \beta\right)\right]\right)
\end{aligned}
$$

where equation (5) exploits the property that $S(t, x, \beta)=\prod_{i=1}^{t-1}[1-h(i, x, \beta)]$. Equation (5) is the likelihood function for any flow sample of discrete durations.

To introduce stock sampling, let the set $\mathrm{C}$ be the set of careers that were in progress when data collection began. For these observations, we know that the career i has lasted for $r$ years before the panel begins so that the probability that the total career length will be $t$ is simply given by

$$
\frac{f(t, x, \beta)}{S(r, x, \beta)}=\left(\prod_{i=r}^{t-1}[1-h(i, x, \beta)]\right) h(t, x, \beta) .
$$


Since we are sampling careers that are already in progress, these observations enter the sample only if the career is at least of length $r$, and we adjust by the conditional probability of the career having length $\mathrm{r}$. With the addition of these observations, we may write the likelihood function as

$$
\begin{aligned}
L(\beta)=\prod_{i \in A}\left(\prod_{j=1}^{t_{i}-1}\left[1-h\left(j, x_{i}, \beta\right)\right] h\left(t_{i}, x_{i}, \beta\right)\right) \times \prod_{i \in B}\left(\prod_{j=1}^{t_{i}-1}\left[1-h\left(j, x_{i}, \beta\right)\right]\right) \\
\times \prod_{i \in C}\left(\prod_{j=r_{i}}^{t_{i}-1}\left[1-h\left(j, x_{i}, \beta\right)\right]\right) h\left(t_{i}, x_{i}, \beta\right)
\end{aligned}
$$

The third term of the right-hand side of equation (7) reflects the adjustment necessary for the stock sample that end during our panel. Because stock-sampled observations, by definition, must have survived until tenure $r$, that they survived until time r provides no information; their survival is an artifact of the sampling strategy.

In our data, no stock-sampled observations are right-hand censored. Thus, we have expressed the likelihood function as a function of the hazard functions (Berger and Black 2001). All that remains is to specify the form of a hazard function and estimate by means of maximum likelihood estimation. The hazard function is the conditional probability of exiting NASCAR cup, given that the NASCAR cup career lasted until the previous season. The hazard function must have a range from zero to one. In principle, any mapping with a range from zero to one will work. Cox (1972) recommends

$$
\frac{h(t, x, \beta)}{1-h(t, x, \beta)}=\frac{h_{t}}{1-h_{t}} e^{x \beta}=\exp \left(\gamma_{t}+x \beta\right),
$$

which is simply the logit model with intercepts that differ by time periods. The term $\mathrm{h}_{\mathrm{t}}$ is a baseline hazard function, which is common to all. The $x \beta$ term, determined by the 
driver's personal and productivity characteristics, shifts the baseline hazard function, but it affects the baseline hazard function in exactly the same way each period. Berger and Black (1999) consider other hazard functions and find that the results are relatively robust across various specifications of the hazard function. As the logit model is available in many software packages, we follow Cox and use the logit model.

The intuition behind equation (8), when using the logit model for the hazard function, is relatively simple. For each year during the survey in which the driver races in NASCAR, the driver either comes back for another season or ends his career. If the career ends, the dependent variable takes on a value of one; otherwise, the dependent variable is zero. The driver remains in the panel until the driver exits racing or the panel ends. If the panel ends, we say the worker's spell is right-hand censored. Thus a driver who begins his NASCAR career during the panel and races for 6 years will enter the data set 6 times. The value of his dependent variable will be zero for the first 5 years (tenure one through five) and be equal to one for the sixth year.

To illustrate a stock sample, consider another driver who enters the panel with 7 years of NASCAR cup racing tenure prior to 1975, the first year of the panel, then races for an additional 3 years to make a 10 year career. For this driver, we ignore his first 7 years of tenure because he is left-hand censored. As the equation of the likelihood function with stock data indicates, the duration of a NASCAR career prior to the beginning of the panel makes no contribution to the value of the likelihood function. Therefore, only years 8 through 10 will enter the data set with the dependent variable taking on the value zero for year 8 and 9 . In the $10^{\text {th }}$ year it takes on a value of one with this driver appearing in the data set a total of 3 times. Note, for all drivers who are right- 
hand censored, we do not know when their career ends so their dependent variables are always coded as zero.

Because the drivers in the panel have varying degrees of job tenure prior to the beginning of the panel, we identify the hazard function for both long and short careers. The disadvantage to this approach is that the vector $\gamma_{t}$ of equation (8) can be very large. In our study it would require 35 dummy variables. We also run into problems with the Cox technique because we have too few drivers who have long careers. To simplify the computation of the likelihood function and keep the long careers, we approximate the $\gamma_{t}$ vector with a $5^{\text {th }}$ order polynomial of driver's tenure. This reduces the number of parameters to be estimated from 35 to 5 . The hazard function becomes

$$
\frac{h(t, x, \beta)}{1-h(t, x, \beta)}=\Phi(t) e^{x \beta}=\exp (\phi(t)+x \beta),
$$

where $\phi(t)$ is a $5^{\text {th }}$ order polynomial in the worker's tenure. Once again, we choose the Taylor series approximation technique over using tenure dummies, due to the small number of observations for high tenures. This method provides a very flexible specification of the baseline hazard, but does impose more restrictions than Cox's model. $^{1}$

In Table 3, we report the estimates for equation 9. We find that the tenure polynomials are jointly significant. We also find that performance measures influence the likelihood of racing the next season. The more starts, more top fives, and the better

\footnotetext{
${ }^{1}$ When higher order polynomials of the sixth and seventh power are included results do not change. This suggests that a fifth order polynomial is flexible enough to capture the influence of the base line hazard.
} 
the driver's ranking, the less the likelihood of ending a racing career. Wins and top ten finishes, however, are found to be insignificant in this specification due to the colinearity of all the performance measures. Age of the driver is also found to be positive and significant, suggesting that the older the driver, the more likely they will exit racing.

The coefficients on family relation provide some interesting results. To allow for ease of interpretation, we convert the coefficient into a percentage and focus on the magnitude of the effect by using $100[\exp (\beta)-1]$. This conversion gives us the percentage difference in hazard rates between the differing family status. First, we find that fathers are 114 percent more likely to exit earlier in their driving careers than their performance indicates. This seems counter to the results of the first section where fathers clearly are the oldest of the sub groups of racers when ending their career. The combination of these results suggests that racers who have their sons follow them into racing tend to be the best racers. Yet fathers, whose son follows them into racing exit sooner than their counterparts given the same level of performance.

Second, sons are found to 21 percent less likely to exit their careers than their counterparts. This result, however, is statistically insignificant. Although their father exits sooner than their performance indicates, a son's careers is no longer than that of other drivers. This result supports a brand-name loyalty model where a son extends the racing name across generations.

Third, being a first brother is found to have no significant impact on career length in NASCAR. Second brothers, however, are 49 percent less likely to exit NASCAR and have longer careers than their performance indicates. This result suggests that second brothers may free ride on the first brothers' reputation. This result also supports the 
brand name model with second brothers following first brothers into racing and being able to extend their careers longer, due to their family name.

\section{Section 5: Conclusions}

Our results suggest that the $\mathrm{N}$ in NASCAR does not stand for nepotism. If nepotism existed, sons would have longer careers than their performance indicates. Sons, however, do not have longer careers than non family connected drivers, given the same level of performance.

In addition, we find that drivers who have sons or brothers who follow them into racing, are clearly some of the best drivers and have established name recognition. We also find that fathers end their careers earlier than performance indicates when a son enters into cup competition. This could be due to a son's ability to extend a brand name across generations. The extension of a brand name also occurs with second brothers who benefit from the first brother's name and having longer careers than performance indicates. If nepotism exits, it occurs only with the second brothers.

Further research can be conducted to study the value of a family brand name. This value does not have to stop with the families of NASCAR. It could extend to the entertainment industry, politicians, lawyers and family businesses. A first generation may establish the brand name, but following generations must maintain the level of performance to keep the value to the name. 
Table1: Means of Variables

\begin{tabular}{|l|l|}
\hline Father & $\begin{array}{l}0.065 \\
(0.246)\end{array}$ \\
\hline Son & $\begin{array}{l}0.107 \\
(0.309)\end{array}$ \\
\hline First Brother & $\begin{array}{l}0.070 \\
(0.245)\end{array}$ \\
\hline Second Brother & $\begin{array}{l}0.057 \\
(0.232)\end{array}$ \\
\hline Age & $\begin{array}{l}36.84 \\
(8.13)\end{array}$ \\
\hline Starts & $\begin{array}{l}12.87 \\
(12.92)\end{array}$ \\
\hline Wins & $\begin{array}{l}0.34 \\
(1.22)\end{array}$ \\
\hline Top 5s & $\begin{array}{l}1.69 \\
(4.02)\end{array}$ \\
\hline Top 10s & $\begin{array}{l}3.36 \\
(6.03)\end{array}$ \\
\hline Rank & $\begin{array}{l}51.10 \\
(32.24)\end{array}$ \\
\hline Sample Size & 2848 \\
\hline
\end{tabular}

(standard deviation in parentheses) 
Table 2: Means by Family Status

\begin{tabular}{|c|c|c|c|c|c|}
\hline & No Family & Father & Son & $\begin{array}{c}\text { First } \\
\text { Brother }\end{array}$ & $\begin{array}{l}\text { Second } \\
\text { Brother }\end{array}$ \\
\hline Starts & $\begin{array}{l}10.32 \\
(11.95)\end{array}$ & $\begin{array}{l}17.62 \\
(12.38)\end{array}$ & $\begin{array}{l}17.76 \\
(13.05)\end{array}$ & $\begin{array}{l}25.32 \\
(10.32)\end{array}$ & $\begin{array}{l}20.52 \\
(13.77)\end{array}$ \\
\hline Wins & $\begin{array}{l}0.19 \\
(0.90)\end{array}$ & $\begin{array}{l}0.96 \\
(2.15)\end{array}$ & $\begin{array}{l}0.68 \\
(1.67)\end{array}$ & $\begin{array}{l}1.43 \\
(2.38)\end{array}$ & $\begin{array}{l}0.32 \\
(0.92)\end{array}$ \\
\hline Top 5s & $\begin{array}{l}1.06 \\
(3.19)\end{array}$ & $\begin{array}{l}3.81 \\
(6.21)\end{array}$ & $\begin{array}{l}3.24 \\
(5.43)\end{array}$ & $\begin{array}{l}5.92 \\
(6.05)\end{array}$ & \begin{tabular}{|l}
2.04 \\
$(3.99)$
\end{tabular} \\
\hline Top 10s & $\begin{array}{l}2.25 \\
(5.00)\end{array}$ & $\begin{array}{l}6.43 \\
(8.21)\end{array}$ & $\begin{array}{l}5.99 \\
(7.69)\end{array}$ & $\begin{array}{l}10.45 \\
(7.69)\end{array}$ & $\begin{array}{l}4.31 \\
(5.91)\end{array}$ \\
\hline Rank & $\begin{array}{l}56.85 \\
(31.48)\end{array}$ & $\begin{array}{l}37.28 \\
(33.49)\end{array}$ & $\begin{array}{l}38.17 \\
(30.67)\end{array}$ & $\begin{array}{l}23.20 \\
(20.20)\end{array}$ & $\begin{array}{l}38.63 \\
(27.46)\end{array}$ \\
\hline $\begin{array}{c}\text { Sample } \\
\text { Size }\end{array}$ & 2080 & 185 & 305 & 198 & 161 \\
\hline $\begin{array}{l}\text { Career } \\
\text { Length }\end{array}$ & $\begin{array}{l}5.21 \\
(5.59)\end{array}$ & $\begin{array}{l}15.46 \\
(9.24)\end{array}$ & $\begin{array}{l}8.82 \\
(9.37)\end{array}$ & $\begin{array}{l}14.00 \\
(9.73)\end{array}$ & \begin{tabular}{|l}
9.54 \\
$(6.96)$
\end{tabular} \\
\hline $\begin{array}{l}\text { Age } \\
\text { Start of } \\
\text { Career }\end{array}$ & $\begin{array}{l}32.42 \\
(7.15)\end{array}$ & $\begin{array}{l}33.00 \\
(7.47)\end{array}$ & $\begin{array}{l}25.28 \\
(5.43)\end{array}$ & $\begin{array}{l}27.60 \\
(5.97)\end{array}$ & $\begin{array}{l}26.80 \\
(4.85)\end{array}$ \\
\hline $\begin{array}{l}\text { Age } \\
\text { End of } \\
\text { Career }\end{array}$ & $\begin{array}{l}38.36 \\
(8.52)\end{array}$ & $\begin{array}{l}45.37 \\
(6.04)\end{array}$ & $\begin{array}{l}34.89 \\
(8.07)\end{array}$ & $\begin{array}{l}43.36 \\
(8.18)\end{array}$ & $\begin{array}{l}38.45 \\
(7.23)\end{array}$ \\
\hline
\end{tabular}

(standard deviation in parentheses) 
Figure 1

\section{Career Exit Plot}

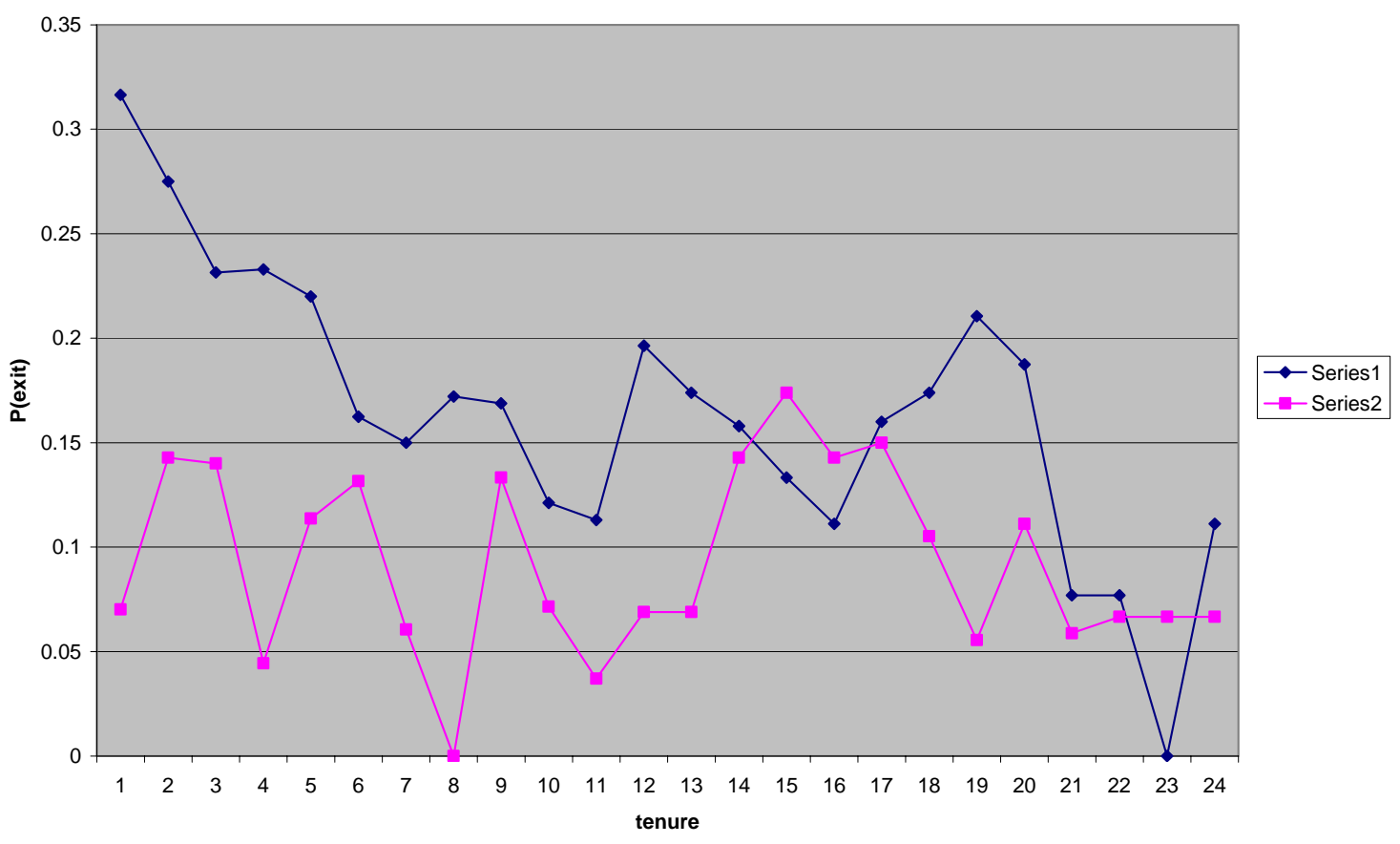


Table 3

\begin{tabular}{|l|l|}
\hline & Specification \\
& \\
\hline Constant & $\begin{array}{l}-72.12 \\
(13.36)\end{array}$ \\
\hline Year & $\begin{array}{l}.035^{* *} \\
(5.76)\end{array}$ \\
\hline Age & $\begin{array}{l}.051^{* *} \\
(5.75)^{* *}\end{array}$ \\
\hline Starts & $\begin{array}{l}-.045^{* *} \\
(3.98)\end{array}$ \\
\hline Wins & $\begin{array}{l}.300 \\
(0.62)\end{array}$ \\
\hline Top 5s & $\begin{array}{l}-.417^{* *} \\
(2.57)\end{array}$ \\
\hline Top 10s & .018 \\
& $(0.28)$ \\
\hline Rank & $.015^{* *}$ \\
& $(5.77)$ \\
\hline Father & $.765^{* *}$ \\
$(3.18)$
\end{tabular}

${ }^{1}$ a fifth order tenure polynomial is included and is jointly significant

*significant at the 95\% level

$* *$ significant at the $99 \%$ level 


\section{Bibliography}

Becker, Gary 1971. “The Economics of Discrimination” Second Edition, University of Chicago Press.

Becker, Gary 1962. "Investment in Human Capital: A Theoretical Analysis” Journal of Political Economy, vol.70, no.5 pp. 9-49.

Berger, Mark C. and Dan A. Black. 1999. "The Duration of Medicaid Spells: An Analysis Using Flow and Stock Samples" The Review of Economics and Statistics, vol.80, no.4, pp. 667-674.

Berger, Mark C., Dan A. Black, and Frank Scott, 2005 "Is There Job Lock? Evidence from the Pre-HIPAA Era" Southern Economic Journal, vol.70 no.4 pp.953-976

Groothuis, Peter A. and J. Richard Hill 2004 "Exit Discrimination in the NBA: A Duration Analysis of Career Length, Economic Inquiry, vol.42 no.2. pp. 341-349.

Laband, David N. and Bernard F. Lentz, 1983a "Like Father, Like Son: Toward an Economic Theory of Occupational Following, Southern Economic Journal, vol.50, no.2 pp.474-493

Laband, David N. and Bernard F. Lentz, 1983b "Occupational Inheritance in Agriculture” American Journal of Agricultural Economics, Vol.65, no.2, pp.311-314.

Laband, David N. and Bernard F. Lentz, 1985 "Favorite Sons: Intergenerational Wealth Transfers Among Politicians” Economic Inquiry,

Laband, David N. and Bernard F. Lentz, 1990 "Family Tradition in Professional Baseball: An Economic Interpretation” Sportometrics, TexasA\&M University Press.

Laband, David N. and Bernard F. Lentz, 1990 "Entrepreneurial Success and Occupational Inheritance among Proprietors” The Canadian Journal of Economics, vol.23, no.3 pp. 563-579.

Laband, David N. and Bernard F. Lentz, 1990 "Why so Many Children of Doctors Become Doctors: Nepotism vs. Human Capital Transfer” Journal of Human Resources, vol.24, no.3 pp. 396-413.

Laband, David N. and Bernard F. Lentz, 1992 "Self-Recruitment in the Legal Profession" Journal of Labor Economics, vol. 10, no.2, p182-201

Laband, David N. and Bernard F. Lentz , 1995 "Workplace Mentoring in the Legal Profession” Southern Economic Journal, vol.61, no.3 pp.783-802. 